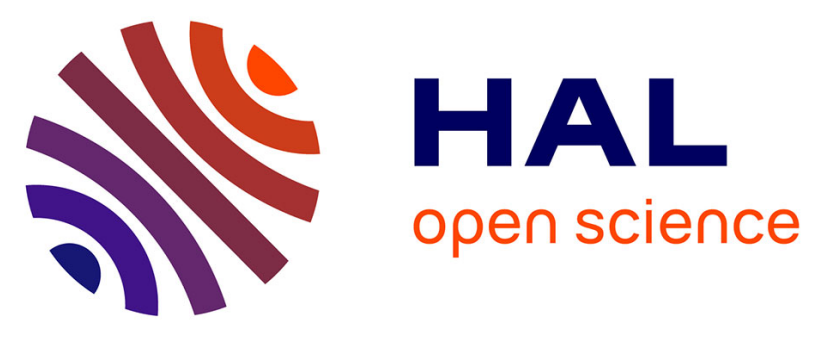

\title{
GAMA: a spatially explicit, multi-level, agent-based modeling and simulation platform
}

\author{
Alexis Drogoul, Edouard Amouroux, Philippe Caillou, Benoit Gaudou, \\ Arnaud Grignard, Patrick Taillandier, Maroussia Vavasseur, Duc-An Vo, \\ Jean-Daniel Zucker
}

\section{To cite this version:}

Alexis Drogoul, Edouard Amouroux, Philippe Caillou, Benoit Gaudou, Arnaud Grignard, et al.. GAMA: a spatially explicit, multi-level, agent-based modeling and simulation platform. 11th International Conference on Practical Applications of Agents and Multi-Agent Systems PAAMS 2013, May 2013, Salamanque, Spain. 4 p., 10.1007/978-3-642-38073-0_25 . hal-02749621

\section{HAL Id: hal-02749621 \\ https://hal.inrae.fr/hal-02749621}

Submitted on 3 Jun 2020

HAL is a multi-disciplinary open access archive for the deposit and dissemination of scientific research documents, whether they are published or not. The documents may come from teaching and research institutions in France or abroad, or from public or private research centers.
L'archive ouverte pluridisciplinaire HAL, est destinée au dépôt et à la diffusion de documents scientifiques de niveau recherche, publiés ou non, émanant des établissements d'enseignement et de recherche français ou étrangers, des laboratoires publics ou privés.

$$
\text { Copyright }
$$




\title{
GAMA: a spatially explicit, multi-level, agent-based modeling and simulation platform
}

\author{
Alexis Drogoul ${ }^{1}$, Edouard Amouroux, Philippe Caillou, Benoit Gaudou, \\ Arnaud Grignard, Nicolas Marilleau, Patrick Taillandier, Maroussia Vavasseur, \\ Duc-An Vo, and Jean-Daniel Zucker \\ IRD, UMI UMMISCO 209, 32 av. H. Varagnat, 93143 Bondy, France \\ alexis.drogoul@gmail.com
}

\begin{abstract}
Agent-based modeling is now widely used to investigate complex systems but still lacks integrated and generic tools to support the representation of features usually associated with real complex systems; namely rich, dynamic and realistic environments or multiple levels of agency. The GAMA platform has been developed to address such issues and allow modelers, thanks to the use of a high-level modeling language, to build, couple and reuse complex models combining various agent architectures, environment representations and levels of abstraction.
\end{abstract}

Keywords: Simulation platform, Agent-based modeling, GIS data, Multilevel model

\section{Introduction}

Agent-based modeling (ABM) has brought a new way to study complex systems by allowing to represent multiple heterogeneous entities interacting in a non-linear fashion in a shared environment. Although it is now used in different domains, ABM still struggles with two issues. First the lack of a comprohensive and common representation of the environment(s) in which agents interact, which limits its usefulness for models where the environment itself is to be represented as a complex entity. Secondly a difficulty to go beyond the classical Object-Oriented Paradigm to express interactions between agents at different levels of abstractions (e.g. agents composed of agents). Even though tools have been proposed in the recent years, they are too complex for domain experts to build their models without a strong support from computer sciontists. For instance, building a realistic model that relies on GIS data at different geographical scales still involves complicated coding tasks in most ABM environments.

The GAMA (GIS \& Agent-based Modeling Architecture) modeling and simulation platform has been proposed to address such shortcomings. On one hand, this open source platform allows the definition of agent-based models with complex environment representations and generic multi-level capabilities. On the other hand, it provides field experts, modelers, and computer scientists with a complete modeling and simulation environment for building spatially explicit 


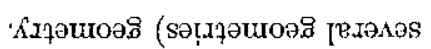

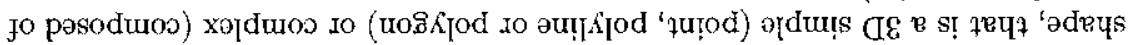

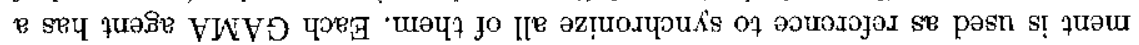

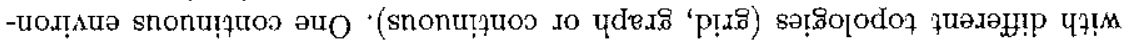
squәшuod!

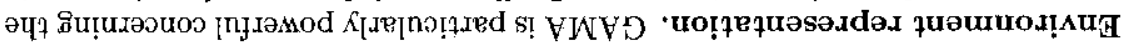

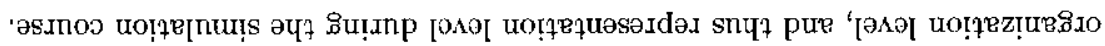

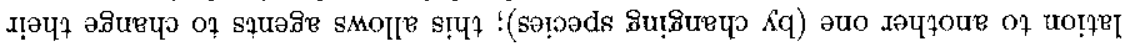

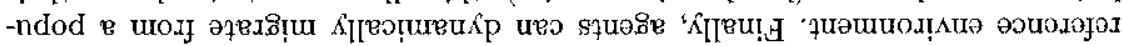

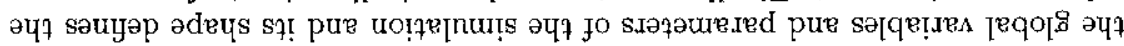

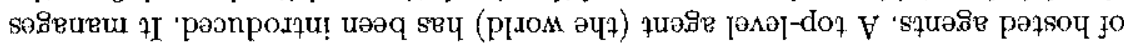

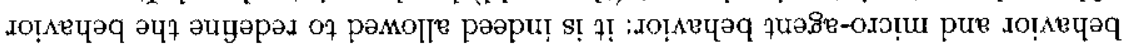
\$า! นәәмұəq suо!

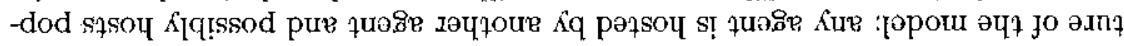

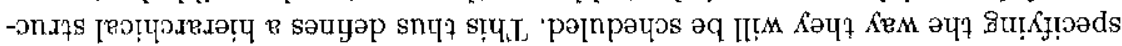

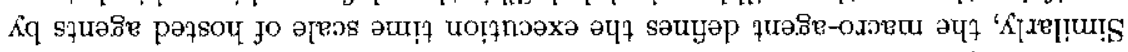

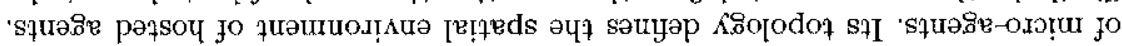

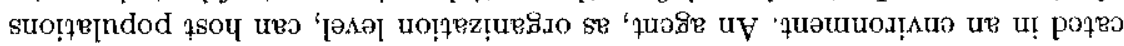

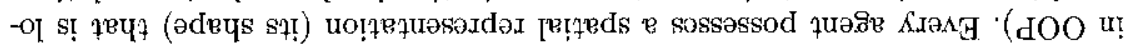

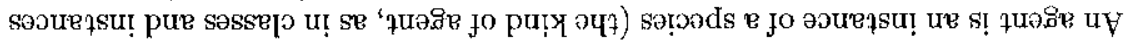

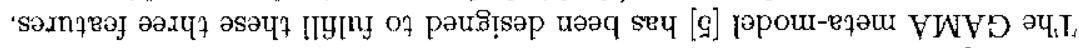

$\kappa_{\text {II }}$

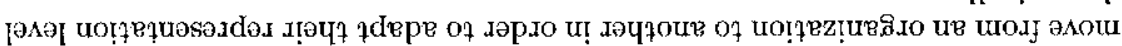

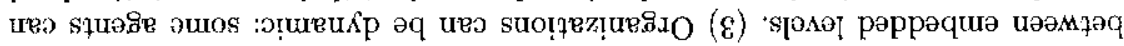

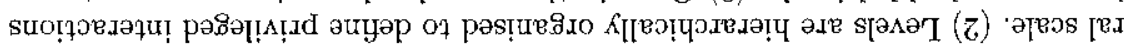

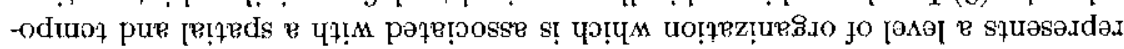

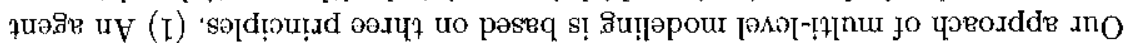

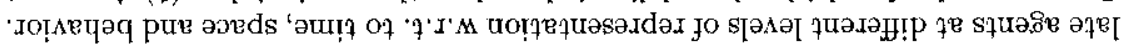

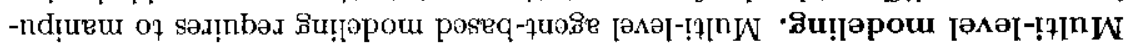

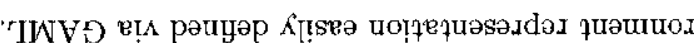

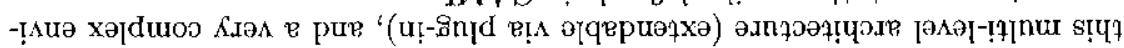

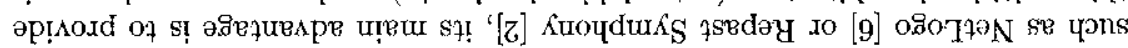

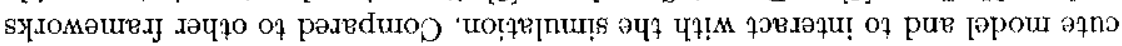

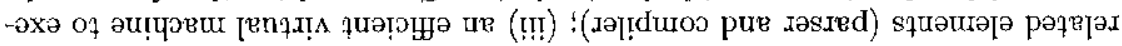

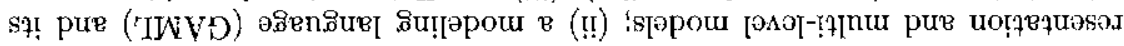
-dex quวuน⿰冫!

\section{asodand u!̣eW $\boldsymbol{Z}$}

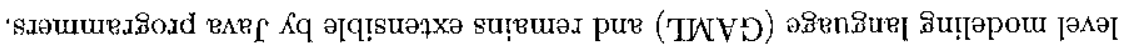

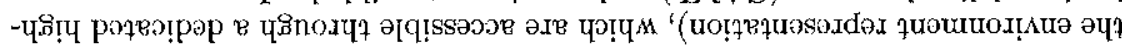

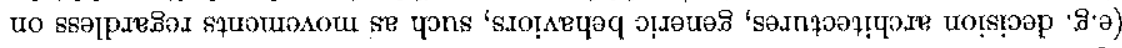

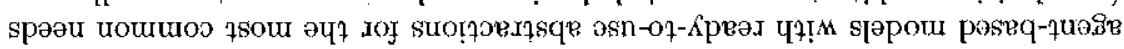


A particularly interesting feature of GAMA is the possibility to create agents and to define their attributes (in particular their shape) from real data using shapefiles. Conversely, this allows the modeler to integrate geographical data into models under the form of active agents (one agents is croated by geometry of a shapefile). In addition, GAMA manages the spatial projection of the data (to get a spatially coherent model) and the reading of attribute values. In order to ease geometries use and manipulation, high-level goometry transformations (e.g. buffer, convex-hull, etc.) and movement primitives (e.g, shortest; path computation) are readily available in GAML.

\section{Demonstration}

GAMA can be used for lots of purposes including teaching, conceptual modeling and applied research. We illustrate its power with applied and abstract uses ${ }^{1}$.

Applied models. GAMA has already been used in various large scale applications that share a strong focus on the interactions between agents and complex environments. Epidemiological models have been devcloped to study avian flu persistence in North Vietnam and rift valley fever propagation in Senegal. It has been used to assess the effectiveness of control policies on the recurrent invasions of insects in the Mekong delta, to simulate rescue management in Hanoi after an earthquake or evacuation organisation in case of a tsunami in Nha Trang (Vietnam). The MAELIA project [3] uses it to study socio-ecological impacts of water management policy in the Adour-Garonne Basin (France).

GAMA can manage a large number of agents for real-scale applications, for example, nearby 200000 for the MIRO model (Figure 1) [1]. This model addresses the issue of sustainable cities by focusing on one of its very central components, daily mobility. Therefore, improving urban accessibility merely results in increasing the traffic and its negative externalities (congestion, accidents, pollution, noise...), while reducing at the end the accessibility of people to the city. For that, an ABM has been developed and applied to Dijon and Grenoble, two mid-sized cities (nearby 120000 inhabitant) in France. The simulator is used to realise scenarios determined by geographers for quantifying, for example, service accessibility and to organise serious gamo sessions for identifying cities management strategies.

Abstract models. As presented in previous section, GAMA offers several modeling capabilities, liko multi-level simulation, seamless integration of GIS Data or extensible architecture with plugin. Very simple conceptual models can be developed and used for demonstration or conceptual proof. For example, the multi-level architecture can be illustrated by a flocking example with Flock agent dynamically created when nearby boids converge (an illustration can be watched

\footnotetext{
${ }^{1}$ Link to a video: http://code.google.com/p/gama-platform/wiki/VideosPresentation
} 


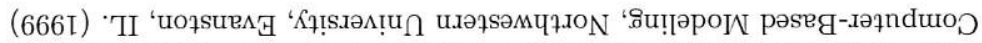

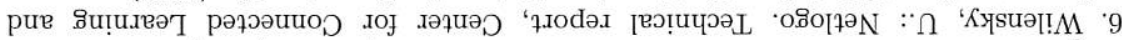

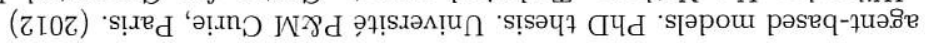

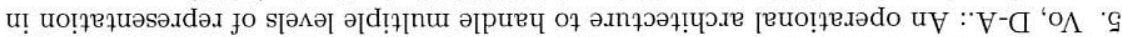

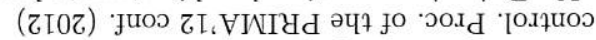

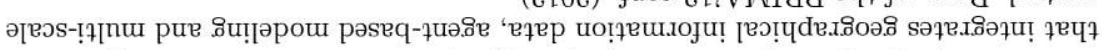

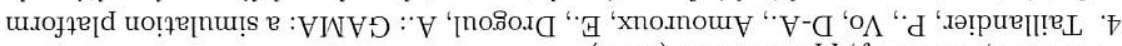

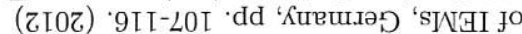

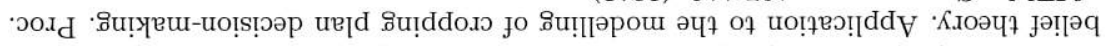

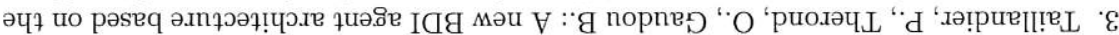

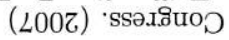

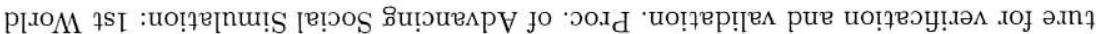

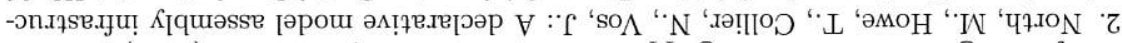

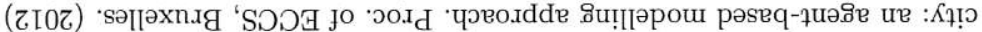

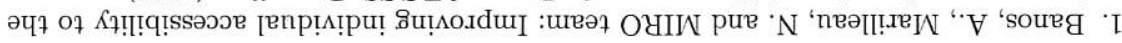

งәวนวләЈәч

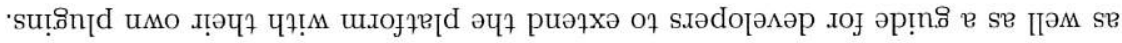

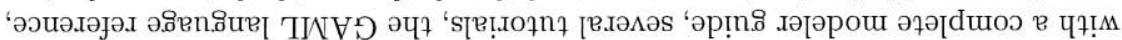

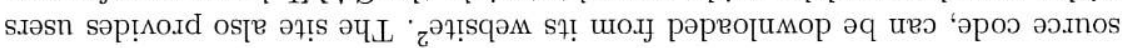

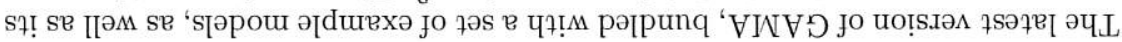

uoțsnjouo

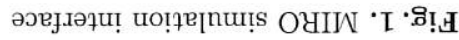

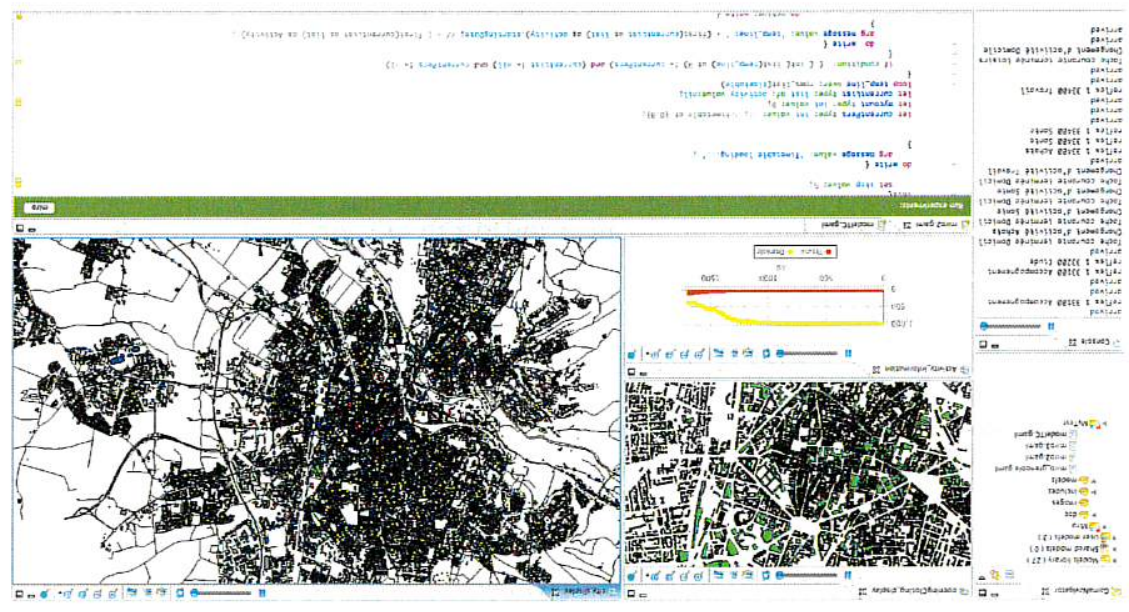

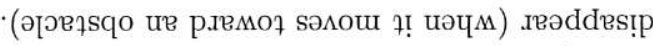

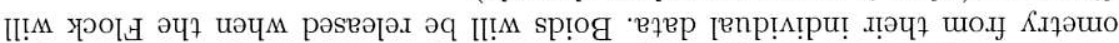

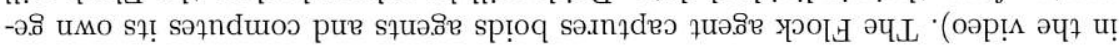

